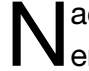
ach den ablehnenden Volksentscheiden in Frankreich und den Niederlanden zum Verfassungsentwurf scheint die EU mit dem Scheitern des Finanzgipfels endgültig in eine schwere Krise gestürzt. Länder mit Hoffnungen auf einen Beitritt sehen ihre Chancen schwinden. Vielfach wird befürchtet, der erreichte interne Integrationsgrad sei gefährdet. Sogar ein Auseinanderbrechen der Währungsunion wurde für denkbar gehalten.

In Frankreich, Österreich und Deutschland sind Stimmen laut geworden, die ein Ende der europäischen Integration als politisches Projekt sehen. Die EU drohe stattdessen, sich in eine - allenfalls „veredelte“ - Freihandelszone zurückzuentwickeln. Dem britischen Premier Tony Blair ist vorgeworfen worden, dass er genau dies anstrebe. Vor dem Hintergrund der finanziellen Interessen Großbritanniens habe er den Gipfel mit der Forderung nach einer Rückführung der Mittel für die Gemeinsame Agrarpolitik scheitern lassen, weil er ein anderes Europa wolle.

Es ist müßig, über die Motive von Tony Blair zu spekulieren. In seiner Rede vor dem Europäischen Parlament am 23. Juni hat er allerdings keinen Zweifel daran gelassen, dass er eine andere Politik in der EU für erforderlich hält, um den Herausforderungen gerecht zu werden, vor denen Europa in einer sich schnell wandelnden Welt steht. Er hat zudem darauf hingewiesen, dass es ein eklatanter Widerspruch sei, für eine Erweiterung der EU um neue Mitgliedstaaten einzutreten, sich aber gleichzeitig gegen eine weitere Öffnung und Liberalisierung im inneren des erweiterten Wirtschaftsraumes zu sperren, wie es einige Länder tun. Der Zielkonflikt zwischen Erweiterung und Vertiefung scheint in der 408

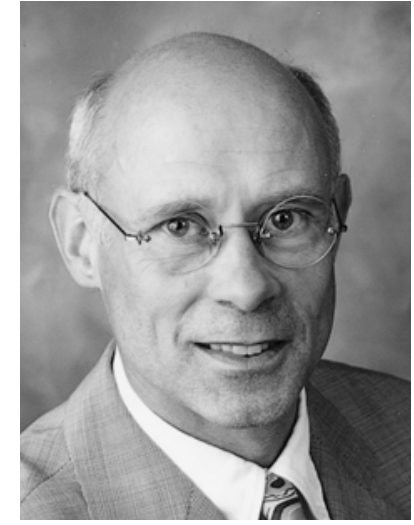

Konrad Lammers

\section{EU: Vertiefung oder Erweiterung?}

Tat die eigentliche Ursache der Krise der EU zu sein. Sollte er nicht gelöst werden, wird er auch die Zukunft der Union bedrohen.

Der Beitritt der mittel- und osteuropäischen Länder hat weitreichende Folgen für den inneren Integrationsprozess sowie für die alten Mitgliedsländer. Sowohl die EU als Ganzes, aber insbesondere die großen kontinentaleuropäischen Länder Deutschland, Frankreich und Italien waren vollkommen unvorbereitet auf die Erweiterung und sind es weitgehend auch heute noch. Zwar ist auf lange Sicht die vollständige Integration der Produkt- und Faktormärkte im erweiterten Wirtschaftsraum für jedes Land, also auch für die alten Mitgliedsländer, von Vorteil. Diese Vorteile lassen sich aber nur realisieren, wenn innerhalb der Länder tiefgreifende Strukturanpassungen erfolgen.

Anstatt weitreichende innere Reformen rechtzeitig einzuleiten und die Bevölkerung auf die Anpassungserfordernisse vorzubereiten, die mit der Osterweiterung verbunden sind, hat die Politik Initiativen ergriffen, die die konstitutiven Prinzipien des einheitlichen
Binnenmarktes verletzen. Die Beschränkung der Zuwanderung aus den neuen Mitgliedsländern verstößt gegen das Prinzip der Freizügigkeit von Personen. Der Widerstand gegen die Dienstleistungsrichtlinie der Europäischen Kommission zeigt, dass das Prinzip der Dienstleistungsfreiheit keinen hohen Stellenwert hat. Die beabsichtigte oder bereits erfolgte Einführung von Entsenderichtlinien ist ähnlich zu bewerten. Es ist höchst unglaubwürdig, für eine Erweiterung der EU einzutreten und gleichzeitig den Implikationen dieses Prozesses entgegenzuwirken.

Auch der Haushaltsentwurf der EU für die Jahre 2007-2013, der auf dem jüngsten Gipfel unverabschiedet blieb, lässt den Konflikt zwischen Erweiterung und Vertiefung ungelöst. Ausgaben für die Landwirtschaft und die Regionalpolitik sollten die wichtigsten Haushaltsposten bleiben. Ungeachtet der Tatsache, dass Ausgaben in diesen Bereichen sicherlich nicht dazu beitragen, Europa gemäß der Zielsetzung der Lissabon-Stategie zum wettbewerbsfähigsten und dynamischsten Wirtschaftsraum der Welt zu machen, spiegeln sich hierin vor allem die Besitzstände der alten Mitgliedsländer wider. Die Kriterien, nach denen die Mittel in der Agrar- und Regionalpolitik zugeteilt werden, begründen bei Gleichbehandlung aber gerade Ansprüche auf Hilfen für die neuen Mitgliedsländer und für solche, die auf einen Beitritt hoffen.

Auch in der Haushaltspolitik hat die EU bislang keine adäquate Antwort auf das Spannungsverhältnis zwischen Vertiefung und Erweiterung gefunden. Wie auch immer die Motive Tony Blairs für das Scheitern des EU-Gipfels gewesen sein mögen: seine Argumente für eine andere Integrationspolitik sind schwerlich zu widerlegen.

Wirtschaftsdienst $2005 \bullet 7$ 